Technical Report 513

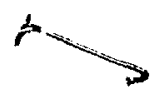

\title{
MASTERY TRAINING: EFFECT ON SKILL RETENTION
}

\section{Stepher, L. Goldberg, Michael Drillings,} and J. Douglas Dressel

\section{TRAINING TECHNICAL AREA}

$\frac{1}{3}$

. 1

$-$

19

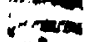

and

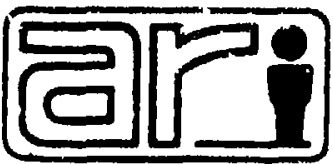

A

U. S. Army

Research Institute for the Behavioral and Social Sciences

March 1881

$$
\begin{array}{llll}
82 & 10 & 27 & 043
\end{array}
$$




\title{
U. S. ARMY RÉSEARCH INSTITUTE FOR THE BEHAVIORAL ANO SOCIAL SCIENCES
}

\author{
A Field Operating Agency under the Jurisdiction of the \\ Deputy Chief of Staff for Personnel
}

JOSEPH ZEIDNER

L. NEALE COSBY

Techuical Director

Colonel, IN

Commander

NOTICES

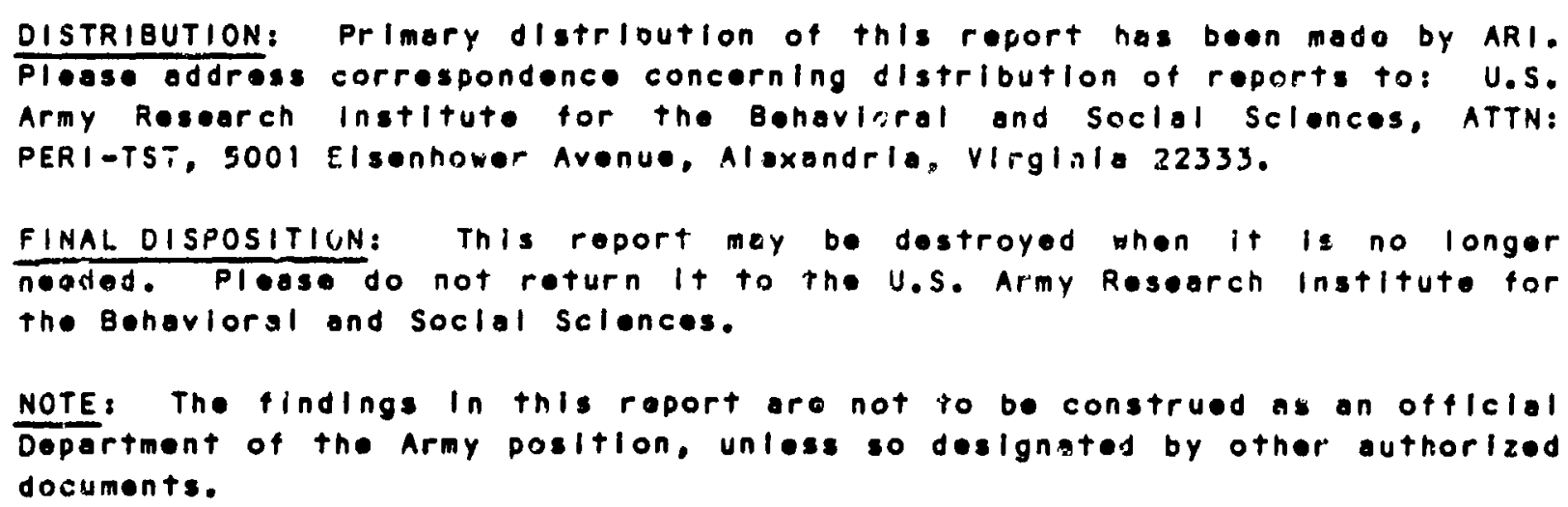


Inclass 1 fied

3ECURITY CLASSIFICATION OF THIS PATE (mion Date Entered)

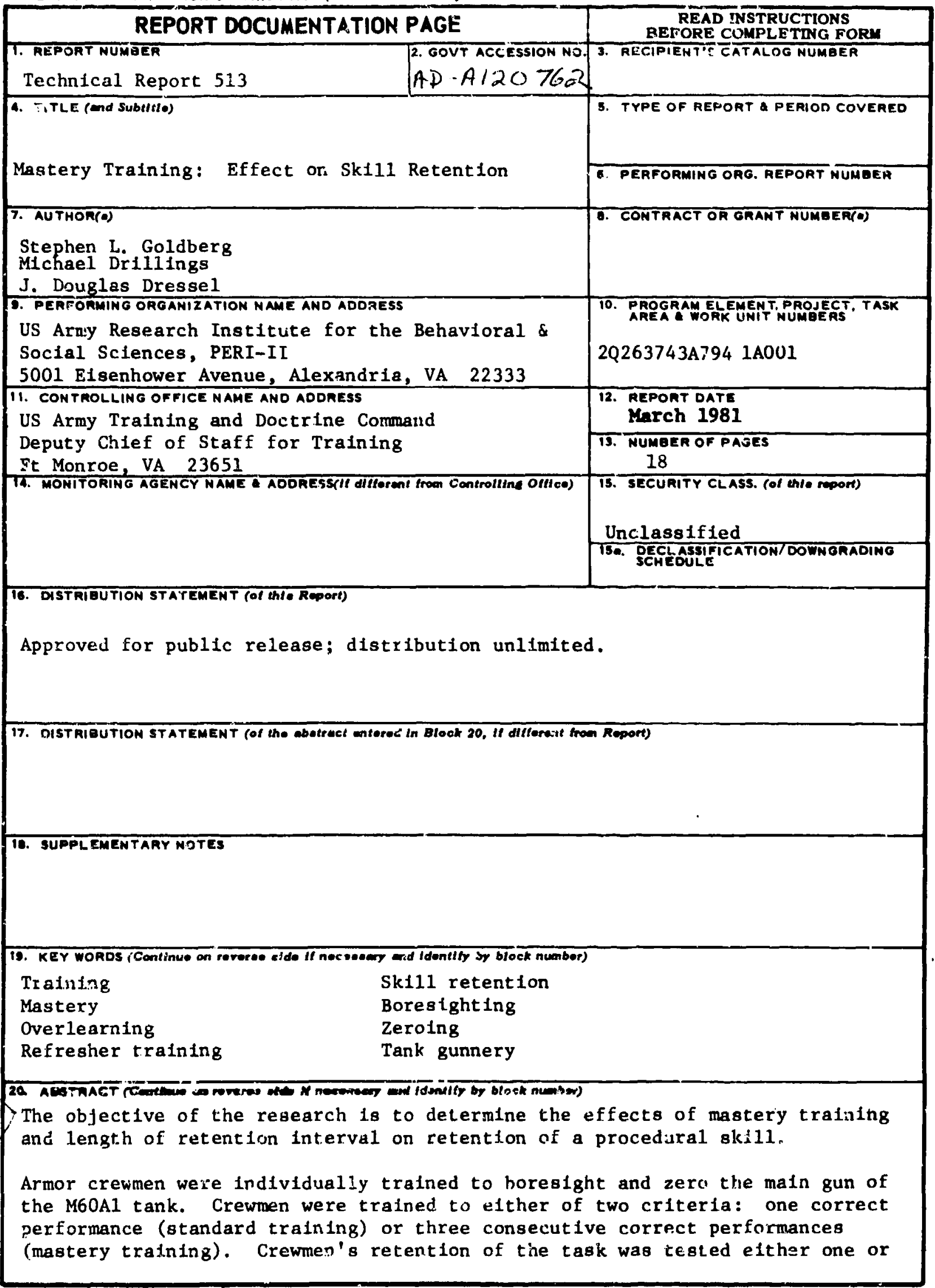


five weeks after training. Each step of the task performance was scored "GO" or yio Go." When a crewman performed a step incorrectly, the scorer would correct the step before permitting the crewman to continue.

The results indicate a cignificant effect of both amount of training and length of retention interval on recali of the task, but no interaction between the variables. Crewmen perform better on the retention test aftar the shorter retention interval or after more intensive training. Differences in performance among the groups are mostly caused by differences on the first retention trial. $T$. ere is no correlation between ability to perform or retain the task and meital category. The reason fyr this result may be the lack of varlance among crewmen's mental categortes.

Although the mastery training provided aided retention of the task, on $1 y 15 \%$ of the mastery trained crewmen were able to perform the task correctly on the first retention trial. The results indicate that mastery training is not efficient for all tasks. Mastery training as compared to refresher training, however, may be useful for tasks that have few steps, must be recalled from memory, must be performed corractly on the first attempt, or for which there are inadequate resources for refresher training. 


\section{MASTERY TRAINING: EFFECT ON SKILL RETENTION}

Stephen L. Goldberg, Michael Drillings, and J. Douglas Dressel

Approved by:

Edgar M. Johnson, Director ORGANIZATIONS AND SYSTEMS RESEARCH LABORATORY

Milton S. Katz' Chief

TRAINING TECHNICAL AREA

U.S. ARMY RESEARCH INSTITUTE FOR THE BEHAVIORAL AND SOCIAL SCIENCES 5001 Eisen1.ower Avenue, Alexandria, Virginia 22333

Office, Deputy Chief of Staff for Personnel

Department of the Armiy

March 1981 
ARI Research Reports and Technical Reports are intended for sponsors of R\&D tasks and for other research and military agencies. Any findings ready for implementation at the time of publication are presented in the last part of the Brief. Upon completion of a major phase of the task, formal recom. mendations for official action rormally are conveyed to appropriate military agencies by briefing or Disposition Forın. 
The nussion of the Training Technical Area of the Army Research Institute for the Behavioral and Social Sciences (ARI) is to provide research support to Army training programs. A major focus of this research is to develop fundamental data and technology necessary to fleld integrated training systems for improving individual fob performance. Such syziems include Skill Qualification Testing (SQT), job performance aids, training courses in schools and in the fleld, performance criterla, and management and feedback systens. This report is one of a series on the task and training factors that affect soldier's ability to retain job skills. The long term goal of the research is to develop criteria for establishing the most approprlate strategles for initially training and retraining all types of Army skills. The work is in response to requirements of the Deputy Chlef of Staff for Training of the Army Training and Doctrine Command (TRADOC). The work was accomplished by ARI personnel under Army Project 2Q263743A794, FY 1980, "Combat Sk111 Development and Retention" for the Deputy Chlef of Staff for Training, TRADOC, with the support of the US Army Armor School, 7th Army Training Center, and the 8th Infantry Division.

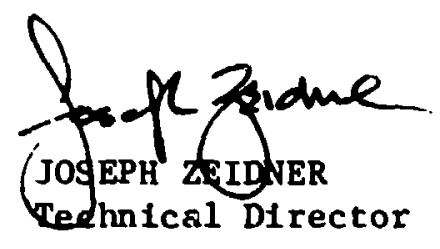


MASTERY TRAINING: EFFECT ON SKILL RETINTION

BRIEF

Requirement:

Determine the effects of mastery training and lengti of retention interval on retention of a procedural skill.

\section{Procedure:}

Armor crewmen were individually trained to boresight and zero the main gun of the M60Al tank. Crewmen were trained to elther of two criterla: one correct performance (standard training) or three consecutive correct performances (mastery training). Crewmer's teteation of the task was tested elther one or five weeks after training. Each step of the task performance was scored "GO" or "NO GO." When a crewman performed a step Incorrectly, the scorer would correct the step before permitting the crewman to continue.

Findings :

The results 1ndicate a significant effect of both amount of training and length of retention interval on recall of the task, but no interaction between the variables. Crewmen perform better on the retention test after the shorter retention interval or after more intensive training. Differences in performance among the groups are mostly caused by differences on the first retention trial. There is no correlation between abiifty to perform or retain the task and mental category. The reason for this resuit may be the lack of variance among crewmen's mental categorles.

\section{Utilization of Findings:}

Although mastery training aids retention of this tagk, at 111, only 15 percent of the mastery trained crewmen are able to perform the task correctly on the first retention trial. The resulta suggest that mastery training may not be the most efficlent strategy for ail tasks. Mastery training as compared to refresher training, however, may be useful for tasky that have few steps, must be recalled from memory, must be performed correctly on the inst attempt, for which there are inadequate resources for refresher traintrig, or for whlch fob alding 18 not feasible. 


\section{Page}

INTRODUCTION . . . . . . . . . . . . . . . . . . . . 1

OBJECTIVE . . . . . . . . . . . . . . . . . . . 2

METHOD . . . . . . . . . . . . . . . . . . . 2

Research Particlpants ...................... 2

Kesearch Design . . . . . . . . . . . . . . . . . 2

Task ............................. 2

Procedure ........................ . 4

RESULTS . . . . . . . . . . . . . . . . . . . . 5

Acquisition ....................... 5

Skill Retention....................... 6

Subtask Analysis ....................... 6

Performance Measure Errors .. . . . . . . . . . . . . 8

Individual Differences .................. 10

DISCUSSION . . . . . . . . . . . . . . . . . . 11

REFERENCES . . . . . . . . . . . . . . . . . . . . . . 13

APPENDIX A. DATA COLLECTION WORKSHEET . . . . . . . . . . . 14

B. QUESTIONNAIRE . . . . . . . . . . . . 15 
Table 1. Grade of Participants. . . . . . . . . . . . . 3

2. Time in Service of Particlpants. . . . . . . . . . . 3

3. Number of Soldiers in Each Condition ............. 5

4. Distribution of Pexformance Measure Errors

During Initial Two Task Attempts... . . . . . . . . . 9

5. Mental Caregory of Particlpants. . . . . . . . . . . . 11

\section{LIST OF FIGURES}

Figure 1. Mean Total Errors . . . . . . . . . . . . . . . 7

2. First Retention Trial Performance............. 7

3. Second Retention Trial Performance. . . . . . . . . . 7 
Army readiness is partly dependent upon the ability of individual soldlers to adequate:y perform the critical tasks that make up their Military Occupacional Speclalty (MOS). The Individual training mission of the Army is to Impart necessary job skills to soldiers and then Insure that these skills are maintalned over the Individual's service time. Carrying out this mission is difficult because Army jobs are composed of thousands of tasks that vary widely in the demands they place on soldiers and resources.

Soldiers currently recelve initlal job training in a US Army Training and Doctrine Command (TRADOC) school or tralning center. They arrive ac an Active Army or Reserve Component unit having had training in a prescribed subset of tasks. Once in their units soldiers are supposed to recelve refresher training on tasks they have learned earlier and onthe-job training on tasks not taught in institutions (Training Circular TC 21-5-7). Problems arise in this system because the training institutions must distribute limited time and resources to train large numbers of tasks that vary in how difficult they are to learn, master, and retain. Refresher training in the unit is difficult because training managers lack sufficient information about when to most effectively schedule training. Also there are conflicting demands on avallable time and training resources.

The Army Research Institute for the Behavioral and Social Sclences (ARI) has been carrying out a research program to determine factors that affect the learning and retention of Army tasks. The overall objective of the program is to provide training managers with optimum strategies for training and maintaining all types of tasks.

ARI has completed a review of the skill retention 1iterature (Schendel, Shields and Katz, 1978) and several retention research projects in Basic Training Sk11ls (Shields, Goldberg, and Dressel, 1979), Typewriting (Hagman, 1979), Thapparal Misatle Skills (Shields, Joyce, and Van Wert, 1979) and Armor Sk11ls (Osborn, Campbel1, and Harr1s, 1979). The research results Indicate that the rate of loss of task proficiency varles widely among tasks. It seems to be a function of the nature of the task, the degree of original learning or the way the task was trained, intervening skill practice, and the extent of job alding employed.

Since both the nature of the task and training methods affect later performance, it is reasonable to assume that use of certain training methods could enhance skill retention for certain classes of tasks. Mastery training is a training method designed to incresse the soldfer's level of original learning. Trainers frequently assume that soldiers have learned a task after they have performed it once successfully. In mastery training the trainee continues to perform the task to some predetermined point past the first successful performance. The continued practice has been shown to enhance retention performance for a number of 
laboratory tasks, both verbal and motor (Kreuger, 1929; Postman, 1962; Melnick, 1971). The application of mastery training in inftial training may be a useful altemative to frequent refresher training if it can be shown that the increased time needed for mastery training results in superior retention performance and is cost effective. Mastery training would be particularly important for combat tasks, such as gunnery skilis, which require use of expensive or scarce resources for tneir training.

In a prior ARI research project which examined retention of common soldiering skills, Shlelds et al. (1979) found that task performance decay rate was related to the number of steps in the task and whether the task contained subtasks. Tasks that had many steps and one or more subtasks had rapld rates of performance decay. In the prescnt research we chose to test the impact of mastery training on retention of a very difflcult task to set an upper bound on the potential benefits of mastery training. The task used was "boresight and zero the main gun of the M60A1 tank." The task contains 27 performance steps within two subtasks.

\section{OBJECT IVE}

Mastery training has been shown to enhance retention in laboratory experiments using verbal and motor tasks. The applicability of this training technique in military settings will depend on the cost effectiveness of mastery training versus refresher training. The objective of this research was to evaluate the effect of mastery training on retention and relearning for a difficult military task "boresight and zero the main gun of the M60Al tank."

METHOD

\section{Research Partictpants}

Forty-two soldiers assigned to an armored battallon in West Germany participated in the research. All of the soldiers were armor crewmen. Five soldiars were tank commanders, 19 were tank gunners, 14 were loaders and 4 were drivers. Tables 1 and 2 present the soldiers' grades and time in the Army.

\section{Research Des1gn}

The regearch design was a $2 \times 2$ factorial design. There were two levels of Inftial training: criteria of one correct and three correct successive task performances. The three successive correct performance condition was considered the mastery condition. There were two retention intervals: one week and $f$ ive weeks. Soldlers were randomiy assigned to training conditions and retention intervals with the exception of those in one company who were forced to be in the one week group because of other training comitments.

Task

Research participants performed two tasks: boresight the M60Al tank and zero the M6OAl tank main gun. For purposes of the research the tasks were treated as one complex cask with two components. The total 
TABLE 1

\begin{tabular}{ccc} 
& Grade of Participants & \\
\hline Grade & Number & Percent \\
\hline E1. & 2 & 4.8 \\
E2 & 1 & 2.4 \\
E3 & 10 & 23.8 \\
E4 & 13 & 31.0 \\
E5 & $\frac{16}{42}$ & 38.0
\end{tabular}

TABLE 2

Time in Service of Participants

\begin{tabular}{ccc} 
Time & Number & Percent \\
\hline Less than 1 year & 3 & 7.1 \\
Less than 2 years & 5 & 11.9 \\
Less than 3 years & 15 & 35.7 \\
Between 3-5 years & 16 & 38.1 \\
More than 5 years & $\frac{3}{42}$ & 7.1 \\
\hline
\end{tabular}


complex task required soldiers to perform 27 discrete steps or performence measures. The boresight subtask consisted of 11 steps. The zero subtask consisted of 16 steps. Boresighting is the procedure whereby the main gun of the tank is aligned with its perisccpe and telescope sights. Zeroing corrects for any systematic error in firing a boresighted main gun. Appendix A contains the score sheet used to test soldiers. The score sheet 1 ists an abbreviated description of the task performance measures. Hughes (1977) describes the boresighting and zeroing procedures in detail.

\section{Procedure}

The research participants first filled out a short questionnaire which gathered demographic data and information on their experience in performing the boresighting and zeroing tasks (Appendix B). Each questionnaire had a number stamped on $1 t$. This number was used to randomly assign soldiers to the two training groups. Soldiers in the mastery training group were required to perform the task correctly three times in a row. The other group performed the task to a criterion of one successful performance. Technical manuals or job aids that might normally be used to perform this task were not allowed to be used in order to increase task performance difficulty for experimental purposes.

Two Army Reseerch Institute researchers individually trained each soldier to perforth the boresighting and zeroing task initially and then retested them following the appropriate retention interval. The researchero Instructed each soldier to perform the dutles that a tank gunner would perform in boresighting and zeroing. The researchers assisted by performing the duties of the tank commander and loader. The soldfers were told to perform the task and describe what they were doing. When possible, they used a boresight target positioned at 1200 meters to perform the task. Fog and rain occassionaliy made it necessary for the experimenters to substitute simulated targets at closer distances. The boresighting and zerolng procedure is such that it is unlikely that target substitution resulted in any systematic error.

As each soldier performed, the researcher scored each task performance measure "GO" or "NO GO". When a soldier made an error, the researcher corrected the performance and told the soldier to continue. At the conclusion of the boresight subtask the soldier was told that he completed boresighting and that he must now zero the main gun. For purposes of this research, the soldiers only simulated zeroing; no live rounds were fired. Each repetition of the task took from 5 to 40 minutes, with the average being ten ininutes.

During acquisition training, soldlers continued to perform the entire boresight and zero task until they had correctly performed it the required number of times for their train \pm ing group. 
The procedure for retesting soldiers after a retention intervai was the same as for the acquisttion session, with the exception that all soldiers performed the task to a criterion of two successive correct performances.

Because of personnel turnover and other training requirements, 15 soldiers who had been initlally trained could not be retested. No other soldiers were elluinated from the experiment. Table 3 shows the number of soldiers in each condition who completed the entire experiment.

TABLE 3

Number of Soldiers in Each Condition

\begin{tabular}{ccc}
\hline Retention Period & Level of Training \\
\hline One Week & 10 & Mastery \\
Five Weeks & 12 & 11 \\
\hline
\end{tabular}

RESULTS

The dependent measures used for the boresighting and zeroing task were the number of trials crewmen need to reach criterla, the total number of errors on all trials, and number of performance measures correct on the firat three retention trials.

Acquisition

Assignments to experimental groups were random. One-way analyses of varlance were performed on the number of errors soldiers made on the first two acquisition trials, total errors to criterion, and number of trials to criterion to test the possibility that some groups had a higher degree of prior skill on the boresighting and zeroing task. In each case there are no significant differences among the groups.

One of the reasons for choosing three successive correct performances as the criterion for the mastery training groups is co estimate the probability with which soldiers could be expected to perform tasics correctly on successive trials. Of the 20 soldiers who recelved mastery training only wo made an error after performing the task correctly once. On the average for both the mastery and standard training groups soldiers perform 2.55 trials prior to their first correct performance. 


\section{Skill Retent1on}

Retention performance on the vores1ght and zero task varies both as a function of level of initial training and retention interval. Figure 1 shows the average total nulaber of errors committed per soldier for the mastery and standard training. groups for one and five week retention intervals. The main effects of training level, $F(1,38)=4.38, \mathrm{R}<.05$, and retention interval, $F(1,38)=8.28, p<.01$. are significant. There is no interaction between training method and retenticn interval.

There is no significant difference in the number of trials it took for the mastery and standard training groups to reach criterion at eithe: retention interval. The observed differences in performance between the groups is mostly the result of performance on the first retention trial. Figures 2 and 3 show the proportion of performance measures passed for the first two retention test trials. Performance on trial one (Figure 2) shows superior performance for mastery training at both retention intervals. The only significant difference which persists into the second retention trial ts between the mastery training-one week retention group and the standard training-five week retention group, the two most divergent conditions. There are no differences in performance on the third trial. Treating trials as a repeared measure in an analysis of variance, (level of training $x$ retention interval $x$ trial) there is a sigrificant interaction of trial $x$ reten+ion interval, $F(1,38)=8.21, p<$ .01 , indicating that the decreased retention caused by the longer retention interval is negated by the learning that occurs on the first retention trial.

In general, soldiers' ability to perform the task successfully after both retention intervals was low. Using proportion of soldiers recelving "GO" for the entire task on the first retention trial as the dependent measure, the mestery training groups have a 15 perrent "GO" rate and the standard trainfing groups have 2.4 percent " $G O$ " rate. Th1s performance would clearly be unacceptable if task conditions required satisfactory performance on the first attempt. Under field conditions, however, it is unilkely that boresighting and zeroing would be performed unaided as was done in the research. Soldiers in the fleld are expected to use appropriate materials that remove much of the memory burden associated with performing the task.

Subtask Analysis

"Boresighting and zeroing the main gun of the M60Al tank" is a compound task that is made up of two tasks that could be performed independent1y. We were interested in whether the second subtask showed poorer performance than the first as found by Shields et. al. (1979), and if each task would show a different pattern of performance under mastery training conditions. 

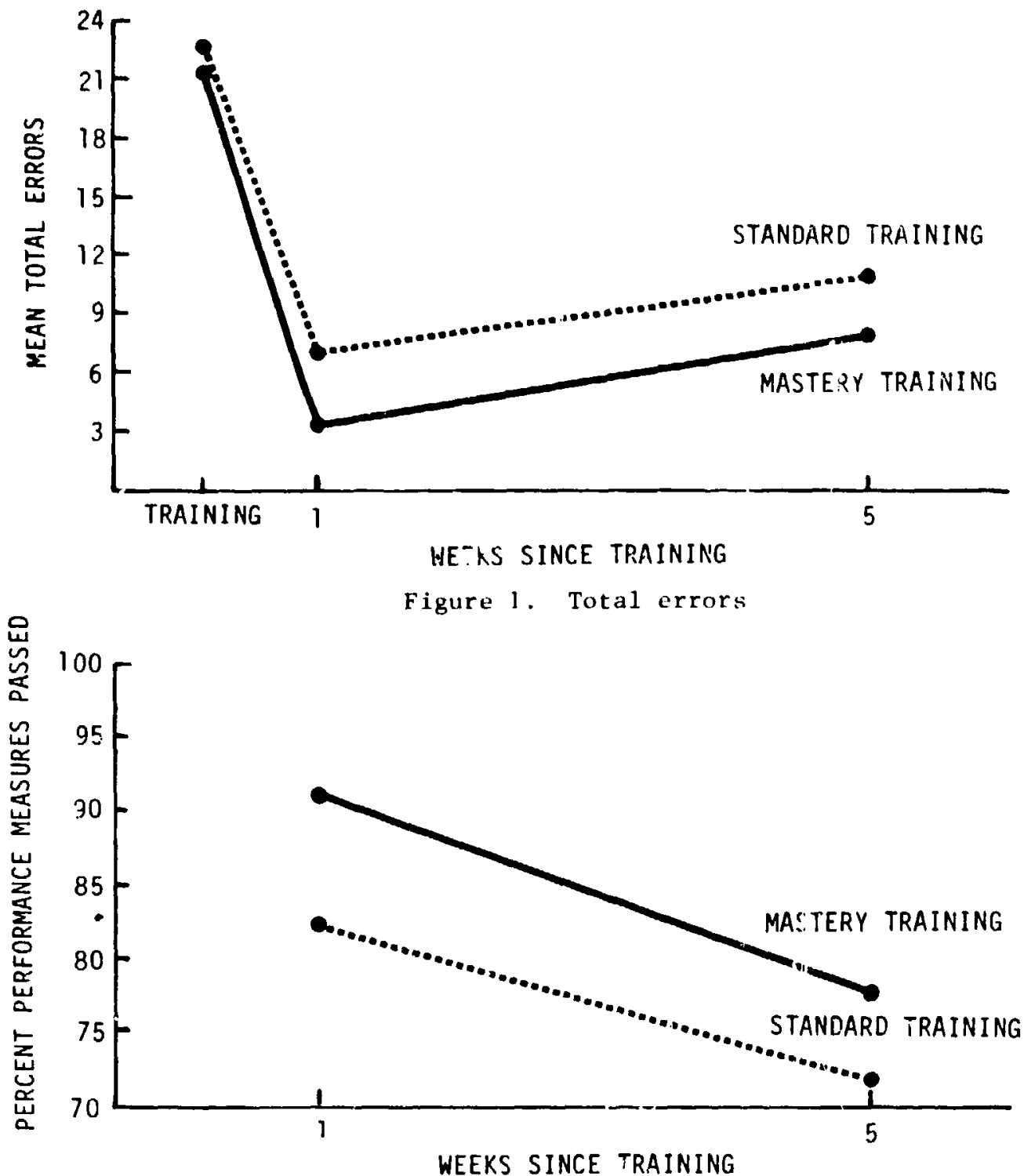

Figure 2. First retention trial performance

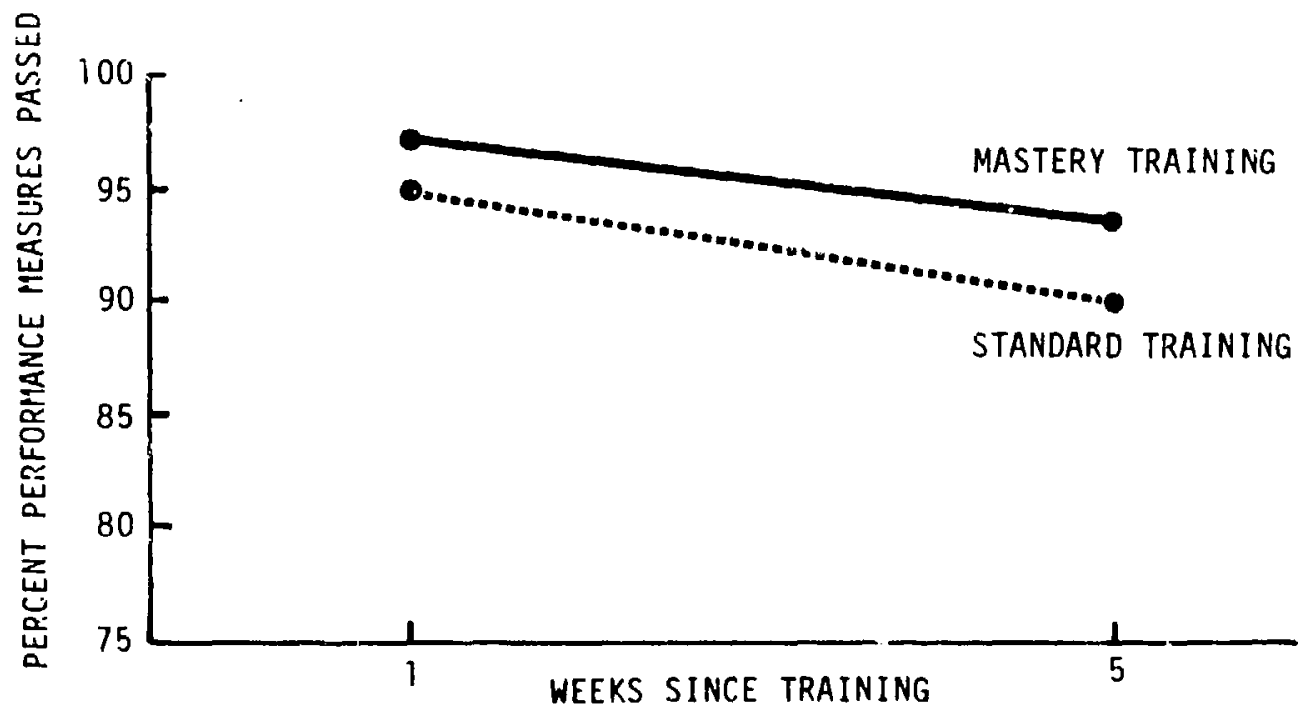

Figure 3. Second retention trial performance 
The zeroirg subtask is more difficult to perform correctly than boresignting durins, both acquisition and retention testing. A matched pairs t-test on the number of attempts for initial subtask success during retention testing indicates significantly $(p<01)$ more zeroing subtask fallures $(\bar{x}=1.6)$ than boresighting fallures $(\bar{x}=1.2)$. The fewer errors on boresighting could be caused by the greater number of steps and therefore higher likelihood of fallure in the zeroing subtask. Also, since soldiers needed 2.4 trlals to acquire the zeroing subtask versus 2.0 for boresighting, they correctly practiced boresighting more t1mes. This occurs because each time soldiers make an error on the more difflcult zeroing subtask they had to repeat performance of both subtasks.

Retention results--Boresighting:

On the first retention trial there is a significant effect of length of the retention interval on the number of measures successfully completed, $F(1,38)=4.51, p<.05$. There are no significant effects of retention interval on later retention trials. The effect of mastery training is not significant. The fallure of mastery training to influence boresighting retention performance is probably caused hy the confounding described above; because of the greater chance of error on zeroing, in effect, all soldiers recelved mastery training on the boresighting subtask.

Retention results--Zeroing:

On the rirst retention test trial there are significant effects of retent Ion interval, $F(1,38)=12.10, p<.001$, and mastery training, $\underline{F}(1,38)=3.96, \mathrm{p}<.05$. The second trial still has a significant effect of retention interval, $\underline{E}(1,38)=4.55, \mathrm{p}<.05$. By the third trial there are no differences in performance due to training or retention interval. Again the benefits of mastery training occur only on the first retention trial, and the effect is limited to increasing the number of task element:s performed correctly. The "GO" rate for the subtask as a whole benefits minimally from the mastery training.

\section{Performance Measure Errors}

Shields, et al. (1979) found that soldiers tended to consistently make errors on the same task elements and that these errors tended to be on performance measures that were most memory dependent. They tended to be steps fin the procedure that were elther not highly related to the steps that preceded them or were not suggested by the hardware. Table 4 shows the errors made by soldiers on the first two trials of acquisition and retencion testing. The items which soldiers failed most frequently in training also proved to be most troublesome in retention. Frequency of performance measure error was ranked for both acquisition and retention trials. Spearman rho coefficients (rho measures the degree of association between two ranked serfes) computed on error rates for task elements during acquisition and retention are $0.73(p<: 05)$ for the boresighting subtask and 0.84 for zeroing $(p<.01)$ indicating that training affects the comparative number of errors on a given task element, but does not change the relative probability of making an error on one element as compared to another. 
TAELE 4

Distribution of Performance Measure Errors During init1: Two Task Attempts

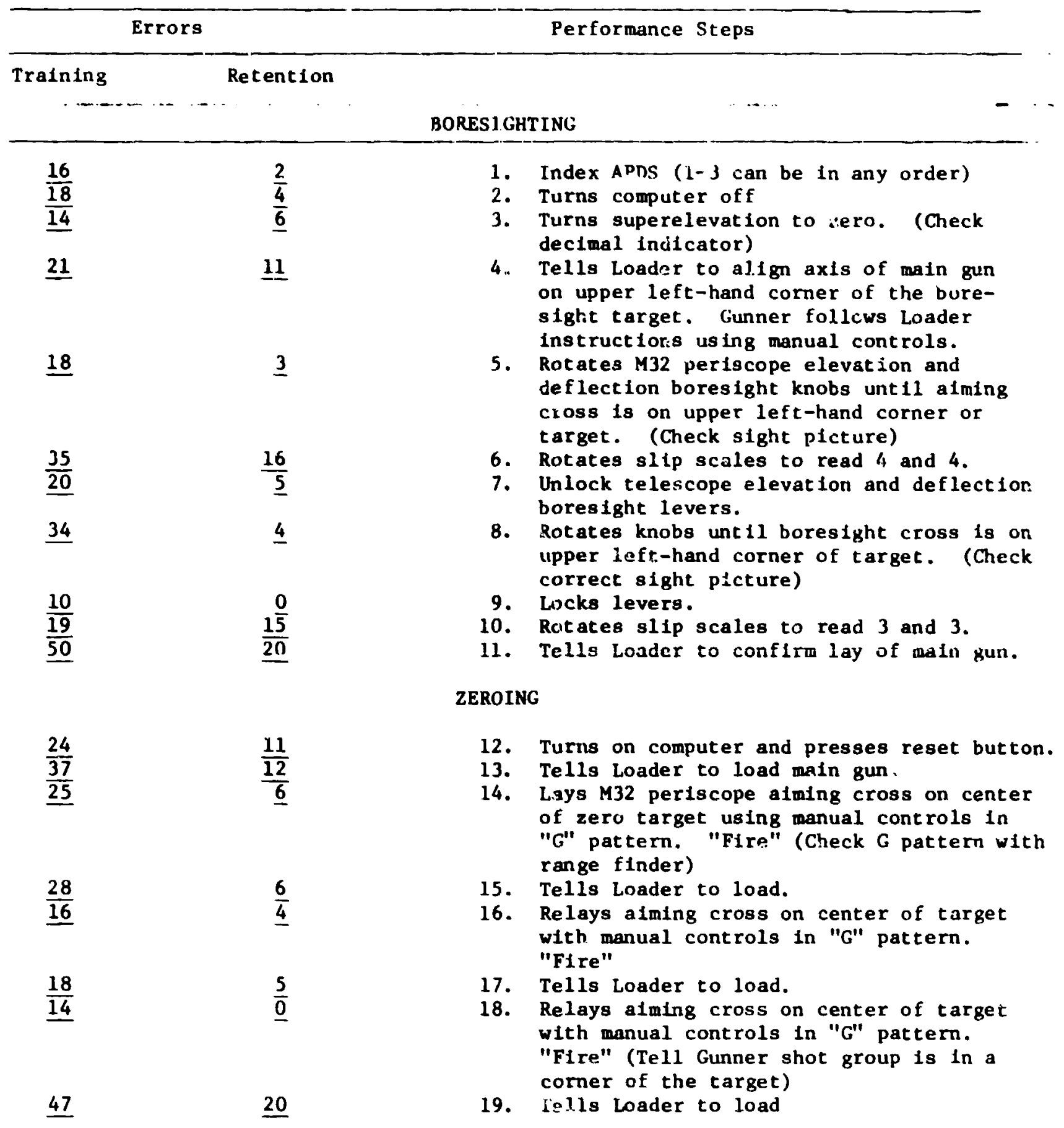




\begin{tabular}{|c|c|c|c|}
\hline \multicolumn{4}{|c|}{ ZEROIING } \\
\hline 57 & 33 & 20 & $\begin{array}{l}\text { Relays alming cross on center of zero } \\
\text { target using "G" pattern and manual } \\
\text { contirls. (Does not fire) } \\
\text { Rotates bores } 1 \text { gnt knobs on }: 32 \text {, } \\
\text { unt } 11 \text { alming cross is in the center of } \\
\text { shot group. }\end{array}$ \\
\hline 41 & $\underline{9}$ & 22. & $\begin{array}{l}\text { Relays to center of zero } \\
\text { target using } \\
\text { manual controls in "G" pattern. "ilre" } \\
\text { (Check with range-finder) "Zero confirmed" }\end{array}$ \\
\hline 62 & 44 & 23. & $\begin{array}{l}\text { Relays to upper left-hand corner of zero } \\
\text { target using manual controls in "G" pattern. } \\
\text { (Check with range-flnde:) }\end{array}$ \\
\hline$\frac{34}{42}$ & $1 \frac{5}{6}$ & $\begin{array}{l}24 \\
25\end{array}$ & 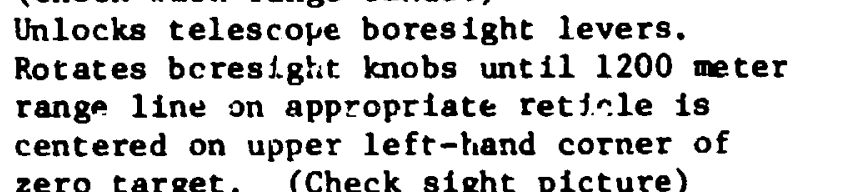 \\
\hline$\frac{27}{32}$ & $1 \frac{1}{16}$ & $\begin{array}{l}26 \\
27\end{array}$ & $\begin{array}{l}\text { Locks levers. } \\
\text { Reads established zero for telescope } \\
\text { and periscope. }\end{array}$ \\
\hline
\end{tabular}

Examination of the task elements where errors are likely again shows that these steps tend to be highly memory dependent with very few cues avallable from prior steps in the procedure or the hardware. For example, during retention testing soldlers err most frequently on the step in the zeroing subtask that involvee relaying the main gun to the upper left hand corner of the zero target using the " $G$ " pattern. Frior to this stcp the soldiers have been simulating firing the main gun. They must now remember to move the gun to a new aiming point using a "G" pattern that is somewhat different from the patterns used previously. The consistency with which errors are made on this type of task element indicates that special emphasis during training should be given to these items and that they should be stressed in refresher training. When resources are linuted it may be most efflclent for training to concentrate on wemory dependent task steps.

\section{Individual Differences}

In addition to sask and training factors, we analyzed the effect of atility level of the individual soldier on acquistition and retention performance. We were able to obtain mental category data from the Military Personnel Center for 32 of the 42 soldiers in the sample. Table 5 shows the distribution of soldiers by mental category. The mean AFQT score and GT score for the sample are 49 and 102 respectively. Correlaring mental category, AFQT or GT score with either acquisition or retention performance results in no significant correlations. There is no cousistent relationship between mental ability and retention performance either within or across experimental groups. The lack of an effect is probably due to 78 percent of the sample being in mental category II. 
The homogeneous nature of the sample may hide differences that would result if there were a greater derree of variation in the measures of meatal ability.

Experlence did make a difference fn acquisition performance. Gunners and loaders made up 80 percent of the sample. Most gunners have been in the Army longer, and hold higher grades than loaders. Gunners are also likely to have more experience w ${ }^{-}$the boresighting and zeroing task. Given these factors it is not surprising that eunins learr to "erinrm the boresighting and zeroing tasks in 1.7 fewer trials than loaders ( $p<$ $.05)$ and make 16.3 fewer errors ( $p<.001$ ) along the way.

TABLE 5

Mental Category of Participants

\begin{tabular}{lcc} 
Category & Number & Percent \\
I & 2 & 6.3 \\
II & 3 & 9.3 \\
III & 25 & 78.1 \\
IV & $\frac{2}{32}$ & 6.3 \\
\hline & DIscussion
\end{tabular}

In the present experiment, mastery training 1 s operationally defined as three consecutive correct performances of the task. In training boresighting and zeroing, each task repetition takes about ten minutes. The mastery training groups, therefore, received approximately twenty more minutes of training tiov: than the soldiers who were trained to a criterion of one correct performance. The extra training benefited subsequent performance. Soldiers in the mastery groups performed a higher percentage of task steps correctly than did the non-mastery trained soldiers. Is this improvement enough to justify the use of mastery training? The answer to this question depends on the costs of training and criticality of the task. For lengthy procedural tasks such as the task examined in this effort, mastery training does not appear to be a cost-effective strategy. Although mastery trained soldiers retained more than non-mastery trained soldiers, still, only $15 \%$ performed the task correctly on the first retention triai. This level of performance is not adequate for operational units. Moreover, for this task, the advantage of refresher training compared to mastery training is shown by the rapid relearnirig that occurs on the first retention trial. 
Stmilar results have been ojtained in ot'ier investigat lons. Both Kyan (1965) and Melnick (1971) found that mastery training or overlearning aided retenticn of a motor task. They both found, however, that short periods of retraining quickly brought the non-overlearning subjects up to the level of performance of the overlearning group. Hammerton (1963) found the same results for a difficult tracking task.

There are a number of possible reasons for the limited value of mastery training. In this effo:t and those cited above, overlearning or mastery trait. sig consisted of subjects performing a relat tveiy small number of repetitions beyond their first successful performance. Flelshman and Parker (1962) had their subjects practice a 21 minute tracking task 17 times over $a$ six week perind. They found little decrement in performance after as long as 24 months of no practice and a high correlation between retention and level of original learning. Apparent]y, when mastery training is more extensive, the benefits are more pronounced. It is probably unrealistic to believe that the Army could afford that degree of practice for any but the most essentlal tasks.

Repetition alone may not be the best type of mastery training. Once a subject reaches some intermediate level of performance, mastery might occur faster and have a more lasting affect if in addition to repeating the tas', the subject also learned more about the task. Added knowledge mifict provide the necessazy means for subjective organization that would ald retention and later recali performance.

Mascery training, compared to more standard Army training methods, did improve performance on the task studied, but the lmprovement would not be considered suffictent to justify the resources required for. routine mastery training on the task. The results indicate that mastery training is probably inefficlent for tasks that are complicated, that have no critical time constraint, and for which resources are avallable to suppor job alling and refresher training. Mastery training may be appropriate for tasks that have few steps, must be reculled from memory, must ine performe: correctly on the first attempt, and for which there are inadequate resources for refresher trai.uing.

Future research in the area of mastery training should sonsider the factors that influence the dacision to employ mastery training as the af proprlate strategv for training particular tasks. Research also needs to adizess the methods of mastery training that result in the best perfurmince. As stated earlier, repetition alone may not be the best or most efficieist method fur training to mastery. 


\section{REFERENCES}

Department of the Arny, Training Circular 21-5-7, Training Management in Battalions. Washingtor, D.C., October 1976 .

Fleishmar, E. A. Parker, S. F. Factors in the retention and relearning. of perceptual-motor skill. Journal of Fxperimental Psychology, $1 ; 62,64,215-276$.

Hagman, J. D. Typewritirg: Retention and Relearning, (Research Report 1211 Alex ndria, VA, US Army Research Institute fur the Bshavioral ano social Sciences (ARI), June 1979.

Hammerton, M. Retention of learning in a difficult trackipg task. Journal of Experimentel Esychology, 1963, 66, 108-110.

Hugles. R. G. Factcrs affecting efficiency of boresighting and zeroing performance in the M60Al tank. (kesearch Problem Review 77-13) Alexandria, VA, US Army Reserch Institute for the Behavioral Sciences, January 1978 .

Kreurer, $v$. C. The effect of overlearning on retention. Journal of Fxperimental Poychology, 1929, 12,71-78.

Melnick, M. J. Effects of overlearning on the retention of gros motor skill. Research Quarterly, 1971, 42,60-69.

Osborn, W. C., Campbell, C. H. Harris, J. H. The retention of tank crewman skills. (Research Report 1234). Alexandria, VA, US Army Research Institute for the Behavioral and Social sciences. December 1979 .

Postman, L. Transfer of training as a function of experimental paradigm and degree of first-list learning. Journal of Verbal Learning and Verbal behavior, $1962,1,109-118$.

Ryan, E. D. Retention of stabilometer performance over extended periods of tine. Research Ouarterly, 1965, 36 $646-51$.

Schende1, J. D., Shields, J. L. Kat $\varepsilon$, M. S. Retention of motor rkills: review. (Technical Paper 3i3) Alexandria, VA, US Army Researcin Institute for the gehavioral and Social Sciences, Sept amber 1978 .

Shields, J. L., Goldberg, S. L. Dressel, J. D. Retention of basic soldiering skills. (Research Peport 1225). Alexandria, VA, US Army Research Institute for the Behavioral and Social Sciences, September 1979.

Shields, J. L., Joyce, R. P.\&Van Wert, J.R. Chaparral gkill retention. (Research Report 1205). Alexandria, VA, US Army Research Institute tor the Behavioral and Social Sciences, Marah 1979. 
APPENDIX A

DATA COLLECTION WORKSHEET

NAME $(8-9)$

$(1-3)$

TRIAL

ID NUMBER

(1) (2)

GO NO 60

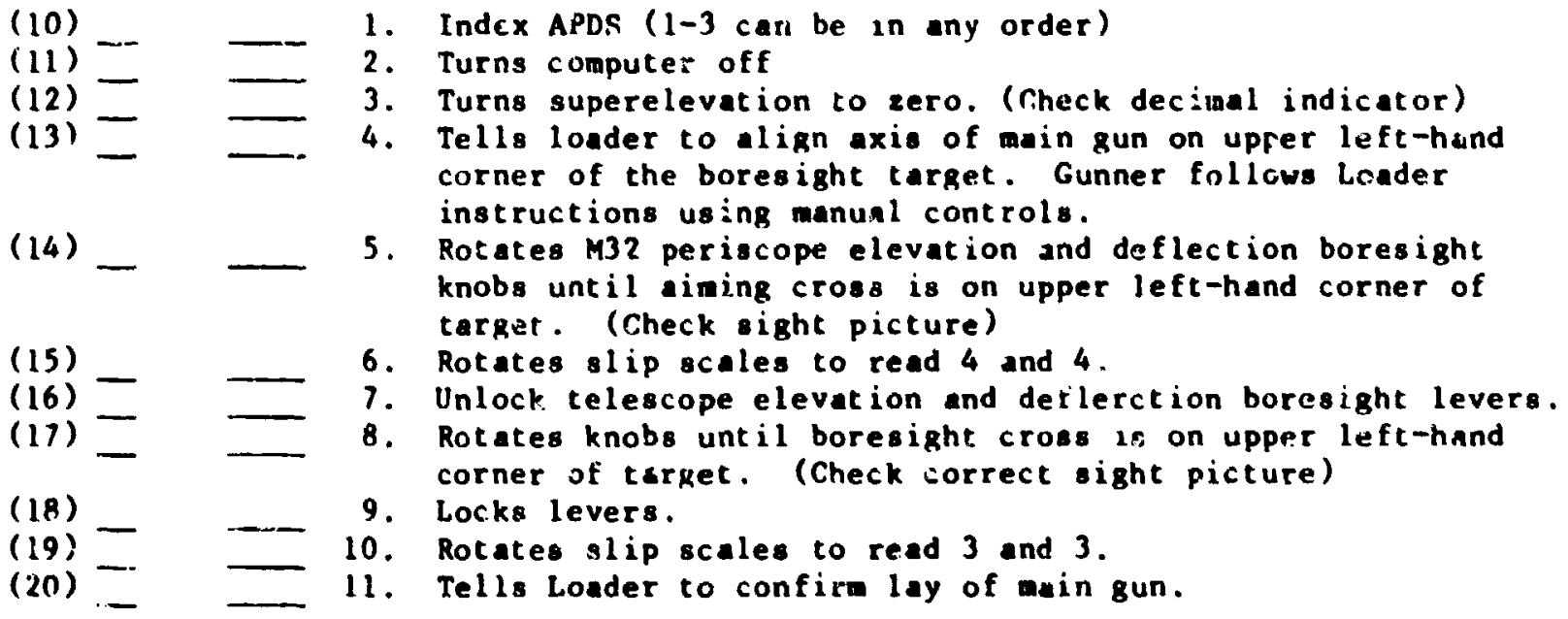

YOU HAVE NOW BORESIGHTED THE MAIN GUN. NEXT YOU WILL ZERO IT. CONTINUE.

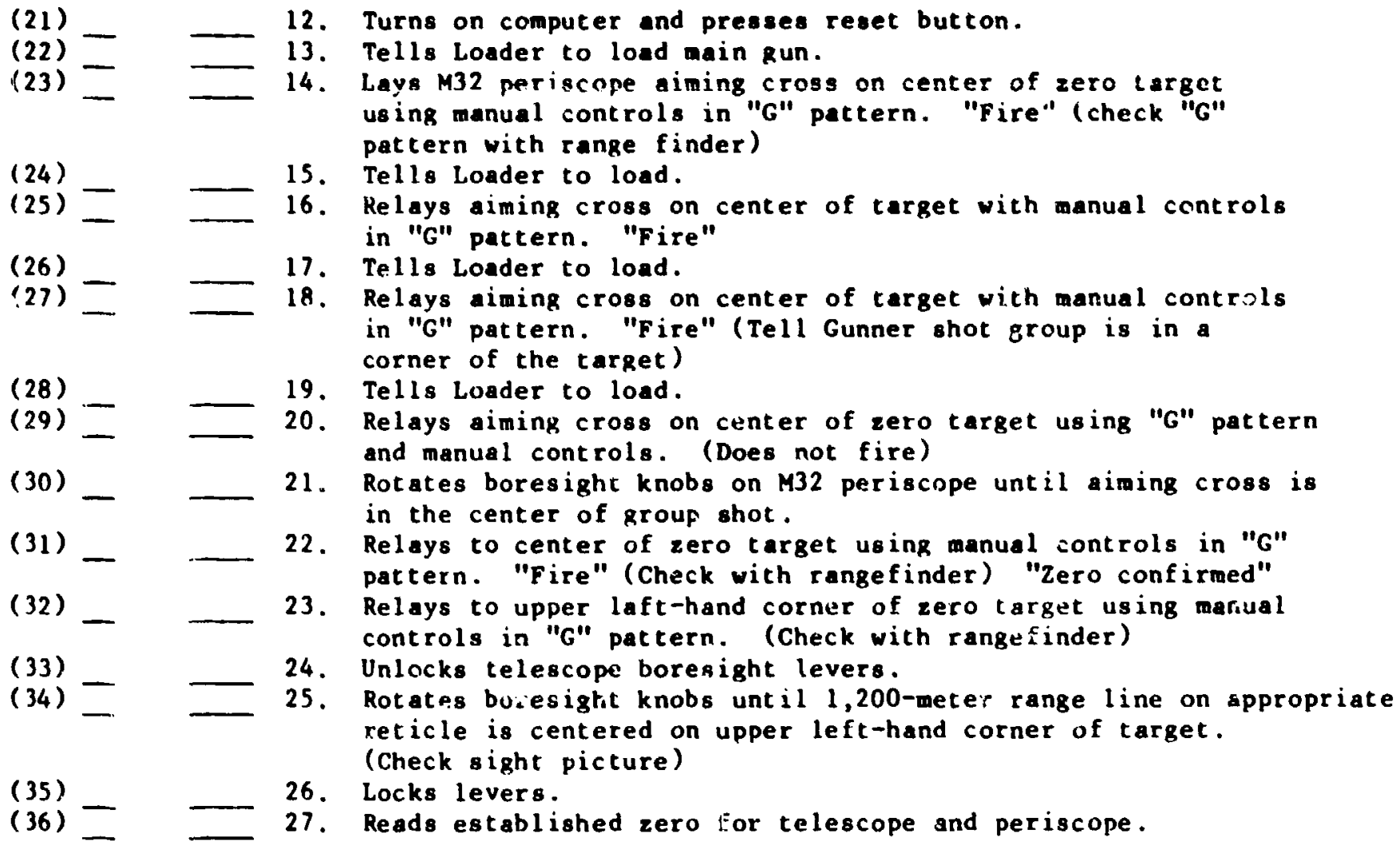


1. Name

2. Company/Platioon

j. Social Securily Nunber $-$

4. What is your grade?

E1

. 4 (1) (4) (2) (5)

E3 (3)

E6-(6)

5. How long have you bean in the Army?

(1) less than 1 year

(2) 1 year to 1 year 11 months

(3) 2 years to 2 years 11 months

(4) 3 years to 5 years

(5) more than 5 years

6. How long have you been a trainer?

(1) less than 1 year

(2) 1 year to 1 year 11 months

(3) 2 years to 2 years 11 months

(4) 3 years to 5 years

(5) mopre than 5 years

7. What is your duty position?

(1) gunner

(2) loader

(3) driver

(4) TC

(5) other

8. How long have you held your duty position?

(1) 0-3 months

(2) 4-6 montins

(3) 7-11 months

(4) 1-2 years

(5) nore than 2 years

9. Which entry-level training course did you attend?

(1) 19E OSUT

(2) $19 \mathrm{~F}$ OSU'

(3) 11E Osu'

(4) IIE AIT

(5) IID AIT

(6) entry level in another Mos 
11. What date did ynu graduate from either AIT or nSUT? month year

12. How many total hours of training have you received on sight reticles during the last six months?
(1) none
(2) 1-3 hours
(3) 4-5 hours
(4) 6-10 hours
(5) more than 10 hours

i3. How recent was your last training on sight reticles?
(1) never had training
(2) last week
(3) this motith
(4) with in 3 months
(5) more then 3 months ago

14. Can you make the appropriate initial lay on the target?

(1) I cannot

(2) I can for some engagements

(3) I can for most engagements

(4) I can for all engagements

15. Can you take the correct lead for moving targets?

(1) I cannot

(2) I can for some engagements

(3) I can for most engagements

(4) I can for all engagements

16. Can you correctly apply burst-on-target (BOT)?

(1) I cannot

(2) I can for some engagements

(3) I can for most engagements

(4) I can for all cngagements

17. Can you correctly adjust fire from a subsequent fire command?

(1) I cannot

(2) I can for some engageinents

(3) I can for most engagements

(4) I can for all engagements 
18. Can you make the standard adjustment when an initial shot is lost?

(1) I cannot

(2) I can for some engagements

(3) I can for most engagements

(4) I can for all engagements

19. During training periods, how often does your crew boresight the main gun?

(1) daily

(2) week ly

(3) 1-2 times a month

(4) less than once a month

(5) never

20. During training periods, how ofien does your crew zero the main gun?

(1) daily

(2) weekly

(3) twice a month

(4) less than once a month

(5) never

21. When you last boresighted and zeroed the main gun, what procedure did you follow?

(1) gunner's instructions

(2) tank conmander's instructions

(3) procedure in the Technical Manual (TM)

(4) other written instructions

(5) platoon leader's instructions

(6) platoon sergeant's instructions

(7) I don't remember or I have never boresighted and zeroed

22. Have you trained on boresighting and zeroing during your unit's sot training?

(1) yes

(2) no

23. If you answered yes to Question 22, how long ago did you last train on boresighting and zeroing?

(1) within the last month

(2) 1-3 months ago

(3) 4-6 months ago

(4) 7 months to 1 year ago

(5) more than 1 year ago 
24. If asked to boresight and zero the main gun of an M60A1 tank, could you do it correctly without help?

(1) very sure I can

(2) fairly su:? I can

(3) fairly sure I can't

(4) very sure I can't

25. When was your last Table 8 ?

month year

26. What was your crew position during your last Table 8 ?

(1) tank commander

(2) gunner

(3) driver

(4) loader

(5) no previous Table 8

27. How did your crew do in its last Table 8?

(1) distinguished

(2) qualified

(3) non-qualified

(4) no previous Table 8

28. What position do you expect to hold during the next Table 8 your crew participates in?

(1) tank commander

(2) gunner

(3) driver

(4) loader 